\title{
Hidatidose policística: cisto hidático calcificado, simulando neoplasia mesentérica, descoberto acidentalmente
}

\author{
Polycystic hydatidosis: casual finding of calcified hydatid cyst \\ simulating mesenteric neoplasm \\ Mário A.P. Moraes'1, Maria de Nazareth M. Sobreira1', Plínio Medeiros Filho', \\ Alexandre Cavalca Tavares ${ }^{1}$ e Maria Iolanda Gomes ${ }^{1}$
}

\begin{abstract}
Resumo É descrito um caso de hidatidose abdominal, sem comprometimento hepático, em paciente do Estado do Acre. O cisto, já em degeneração e parcialmente calcificado, foi descoberto, por acaso, mediante estudo radiológico da coluna vertebral feito para avaliação de hérnia de disco, detectada algum tempo antes. Embora as imagens sugerissem uma neoplasia do mesentério, o achado de acúleos rostelares no conteúdo pastoso da hidátide, removida cirurgicamente, permitiu reconhecer-se a natureza parasitária da lesão.
\end{abstract}

Palavras-chaves: Equinococose neotropical. Hidatidose policística. Echinococcus vogeli. Cisto hidático calcificado.

Abstract A case of abdominal hydatidosis, without hepatic involvement, in a patient from the State of Acre is reported. The hydatid, already in degeneration and partially calcified, was discovered incidentally by a radiologic examination of the vertebral column, carried out for evaluating the state of an intervertebral disk prolapse. Although the images suggested a mesenteric tumor, attached to the intestinal wall, the finding of rostellar hooklets in the dense contents of the cyst, after surgical removal, revealed the parasitic nature of the lesion.

Key-words: Neotropical echinococcosis. Polycystic hydatidosis. Echinococcus vogeli. Calcified hydatid cyst.

Equinococose neotropical ou doença hidática (hidatidose) policística é a infecção devida ao estádio larvar (hidátide) de duas espécies de cestóides do gênero Echinococcus: Echinococcus vogeli (Rausch \& Bernstein 1972) e Echinococcus oligarthrus (Diesing 1963). Ambas produzem hidátides de tipo policístico nos hospedeiros intermediários - espécies várias de roedores silvestres, principalmente a paca (Cuniculus paca) e ratos espinhosos (gênero Proechimys), para E.vogeli, e cutias (gênero Dasyprocta), para E. oligarthrus. Os vermes adultos se alojam, em geral, no intestino de carnívoros silvestres (canídeos e felinos). $\mathrm{O}$ homem adquire o parasito acidentalmente e se comporta, no caso, como hospedeiro intermediário. A fonte de infecção é, quase sempre, o cão de caça ou o cão doméstico alimentados, em sítios de caça, com vísceras de roedores parasitados.

O órgão mais comumente envolvido na hidatidose policística humana é o fígado, mas hidátides podem ser também encontradas nos pulmões ${ }^{14}$. O mesentério é atingido, raras vezes, secundariamente, a partir do fígado. Alguns cistos podem sofrer involução espontânea e calcificação: a hidatidose, em pacientes assim, pouco importando a localização, cursa de forma assintomática, sendo descoberta por acaso, quando o cisto é detectado em estudo radiológico, levado a efeito para outros fins, como aconteceu no caso ora descrito.

A infecção larvar resulta da ingestão de ovos postos pelos vermes adultos, e que contaminam o solo ao serem eliminados com as fezes dos hospedeiros

1. Centro de Anatomia Patológica do Hospital Universitário de Brasília, Brasília, DF.

Endereço para correspondência: Dr. Mário A.P. Moraes. Centro de Anatomia Patológica/ Hospital Universitário de Brasília. Via L2 Norte, SGAN 604/605, Módulo C. 70840-050 Brasília, DF.

Fax: $5561448-5388$

e-mail:caphub@unb.br

Recebido para publicação em 13/3/2001

Aceito em 5/6/2003 
definitivos. Os ovos, depois de ingeridos por um hospedeiro apropriado, abrem-se no duodeno, liberando os embriões hexacantos (oncosferas), providos de acúleos ou ganchos. Com o auxílio dessas estruturas, atravessam os embriões a mucosa e penetram nos capilares venosos da parede intestinal. Arrastados pela corrente sangüínea, chegam ao fígado, onde se implantam. Alguns conseguem atravessar o filtro hepático, caem na veia cava inferior e são levados aos pulmões.

Uma vez nos capilares do fígado ou dos pulmões, transformam-se eles, lentamente, em hidátides - a fase larvar dos equinococos -, estruturas císticas que encerram os protoscoleces, origem dos futuros vermes adultos. Os protoscoleces são também armados de ganchos quitinosos, cuja morfologia é importante para o reconhecimento das espécies do gênero. Os de $E$. vogeli medem de 33 a $41 \mu \mathrm{m}$ de comprimento e têm a lâmina, encurvada, mais longa do que o cabo (2/3 do total), enquanto os de E. oligarthrus medem de 26 a $32 \mu \mathrm{m}$ e neles a lâmina e o cabo têm comprimento quase igual. Por outro lado, os acúleos das demais espécies de Echinococcus são bem menores - os de E. granulosus, espécie encontrada no sul do Brasil, medem de 18 a $22 \mu \mathrm{m}^{3}$.

\section{RELATO DO CASO}

Paciente do sexo feminino, 44 anos, branca, viúva, secretária, natural e procedente de Brasiléia, AC. Em outubro de 1999, veio ao Hospital Universitário de Brasília, por causa de dor na perna direita que, havia três anos, a obrigava a procurar tratamento ortopédico; trazia o diagnóstico de lombociatalgia por hérnia de disco intervertebral e foi encaminhada ao Serviço de Neurocirurgia. Ao exame clínico inicial, mostrou o seguinte: marcha claudicante à direita; dorso-flexão leve do pé e do hálux direitos; reflexo aquileu abolido e sinal de Lasègue presente, ambos à direita. O estudo imagenológico da coluna vertebral, em 25.10.99, revelou compressão do saco dural em L5-S1 e descobriu, inesperadamente, lesão expansiva abdominal, arredondada, medindo $4,5 \mathrm{~cm}$ de diâmetro, com áreas de calcificação, no flanco direito, em posição anterior e à direita de L3-L4. O crescimento aparentava relação com alça do intestino delgado ou com o ceco, podendo corresponder a leiomioma da parede intestinal. Em 19.11.99, uma colonoscopia mostrou mucosa de aspecto normal até o íleo terminal. Hemograma sem alterações.

A paciente negou dor abdominal, perda ponderal ou alteração no ritmo intestinal. Apendicectomia realizada 14 anos antes. Referiu contato com cães no domicílio e animais silvestres no peridomicílio. Eventualmente, alimentava-se de carne de caça.

Em 3.12.99, foi ela submetida à intervenção cirúrgica para retirada da neoplasia abdominal. No ato, foi encontrado e removido um tumor do mesentério, medindo $5 \times 5 \mathrm{~cm}$, duro, móvel e encapsulado. Alta no terceiro dia após a operação.

Exame anatomopatológico. Massa ovóide, pesando $47 \mathrm{~g}$, de cor amarelada e superfície externa rugosa. Ao corte, ficou evidente tratar-se de formação cística, contendo material pastoso, acinzentado, com gratulações duras e brancacentas (Figura 1). A parede do cisto era espessa, branco-amarelada e exibia áreas calcificadas. Microscopicamente, nos cortes, ao lado de extensas áreas amorfas e depósitos de cálcio, havia fragmentos esparsos de membrana anista, estriada longitudinalmente e dobrada em pregas cerebróides (Figura 2). Esses fragmentos assemelhavam-se a restos da membrana laminada de uma hidátide. Pequenas porções foram então retiradas do conteúdo pastoso do cisto, já fixado, comprimidas entre duas lâminas de microscopia e usadas para a pesquisa de ganchos quitinosos. Numerosos acúleos rostelares foram vistos nessas preparações e foram decisivos para o diagnóstico da hidátide e a identificação da espécie - $E$. vogeli-, dado que o cisto, já em avançado estado de degeneração, aparentava ser unilocular, com protoscoleces dificilmente reconhecíveis (Figura 3). Os acúleos foram identificados pelo tamanho, forma e proporções entre os componentes - lâmina, cabo e manúbrio - como pertencentes à espécie Echinococcus vogeli (Figura 4). O local de origem da paciente também apontava para essa espécie.

\section{DISCUSSÃO}

A hidatidose policística é encontrada em vários países da América do Sul e da América Central. Em 1998 eram conhecidos 86 casos distribuídos por 11 países $^{24}$. Desses 86 casos, 32 tinham sido causados por E. vogeli, 3 por E. oligarthrus e nos outros 51 a espécie não pôde ser determinada. Os países com maior número de casos eram Brasil (38 casos dos quais 24 por E. vogeli) e Colômbia (16 casos). A maioria dos casos brasileiros procedia de Estados da Região Amazônica, principalmente Acre e Pará ${ }^{5}$. Em 59 casos, nos quais havia referência à localização dos cistos, apenas $5(8 \%)$ apresentaram envolvimento do mesentério ${ }^{5}$. Este é o terceiro caso diagnosticado no Distrito Federal, nenhum deles sendo autóctone. Em um desses casos a localização era exclusivamente pulmonar $^{1} \mathrm{e}$, embora o paciente tivesse sido medicado com albendazol, 400mg por dia, a medida não surtiu o efeito esperado; o acompanhamento do doente mostrou, ao fim de um ano, regressão apenas parcial das alterações radiológicas pulmonares. Depois de dois anos, novo exame confirmou a persistência das lesões.

Sem lesões hepáticas que pudessem ter sido a origem do cisto no mesentério deste caso, é de supor- 
se que o embrião hexacanto, depois de atravessar a parede do intestino, alojou-se no conjuntivo do mesentério, onde se desenvolveu e, por falta de condições apropriadas, acabou morrendo. A reação do organismo ao material necrosado produziu o encistamento

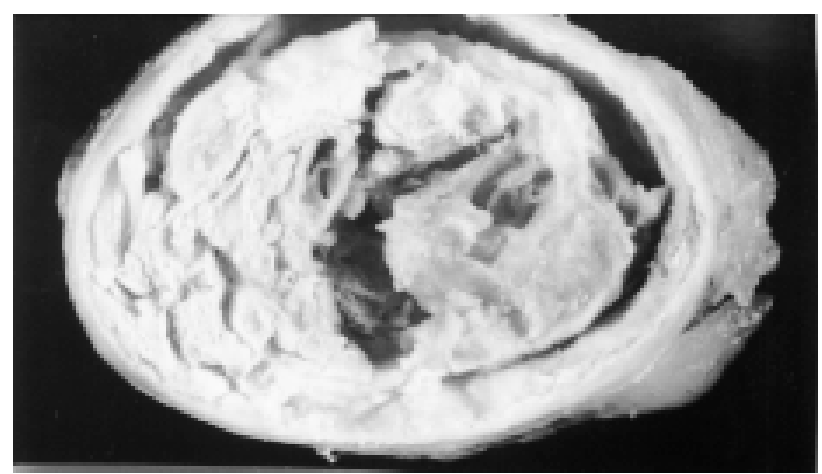

Figura 1 - Superfície de corte do cisto, aberto longitudinalmente, mostrando cápsula espessa que se destaca parcialmente dá massa central, retraída pela fixação.

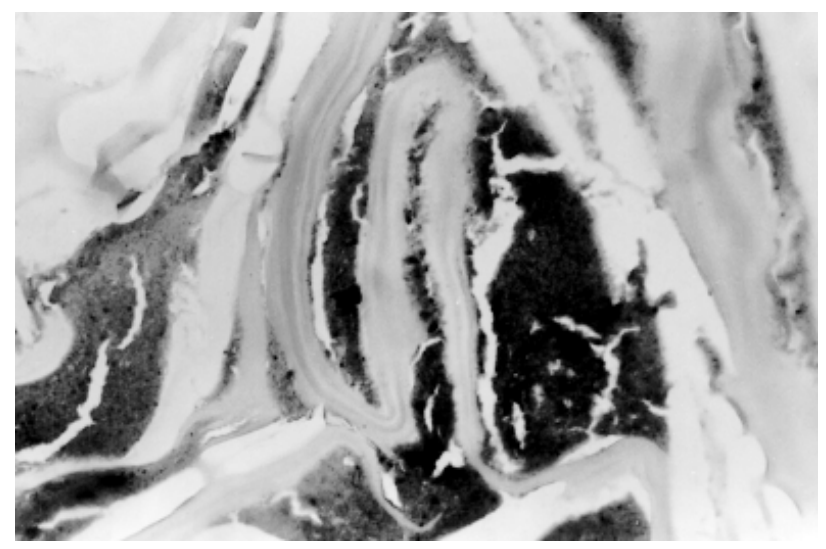

Figura 2 - Fragmentos da membrana laminada entre áreas de calcificação. HE. 100x.

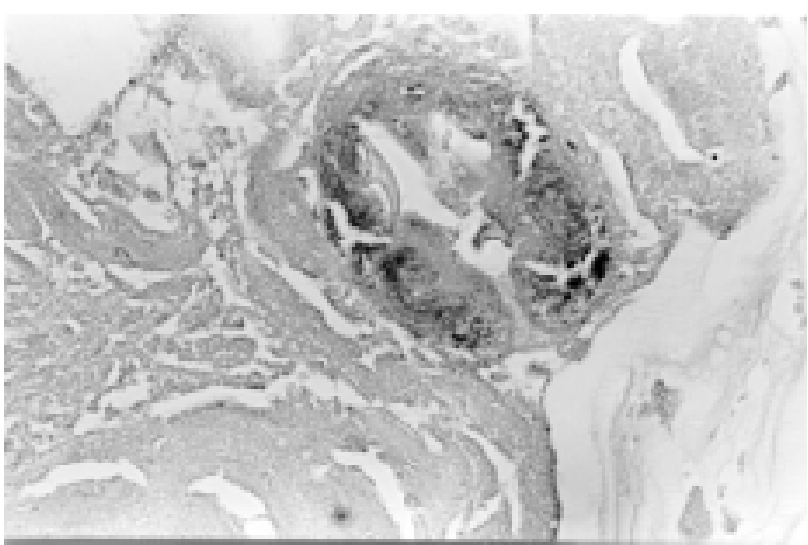

Figura 3 - Restos de um protoscolece, com ganchos rostelares típicos de E. vogeli. HE. 200x.

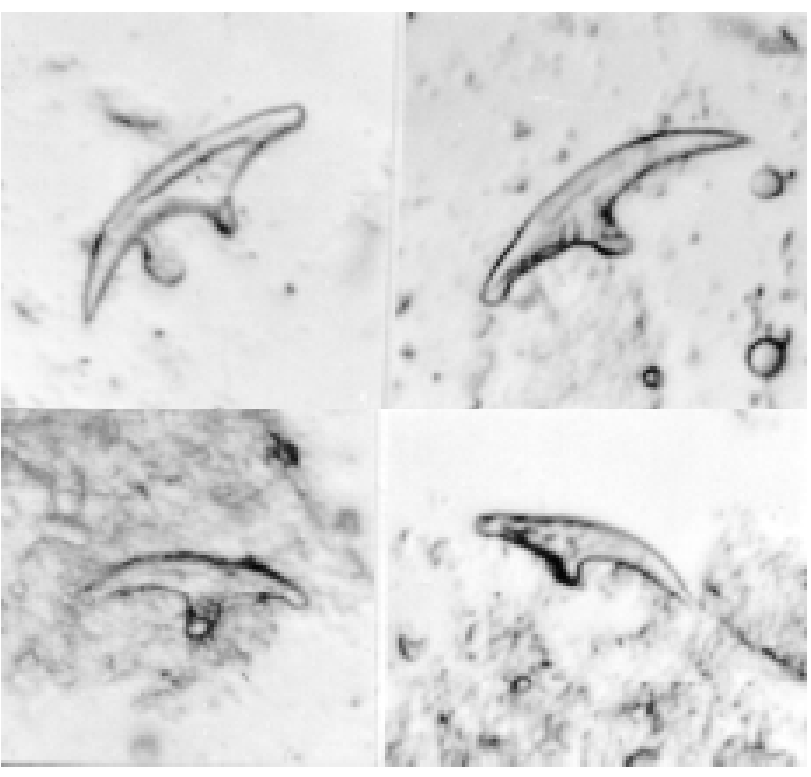

Figura 4 - Acúleos encontrados ao exame direto do conteúdo pastoso do cisto. $800 x$.

\section{REFERÊNCIAS BIBLIOGRÁFICAS}

1. Almeida SCX, Martins RLM, Moraes MAP, Viegas CA, Grilo M. Hidatidose pulmonar policística mimetizando lesões metastáticas: relato de caso. Jornal de Pneumologia 23: 261-263, 1997.

2. Basset D, Girou C, Nozaies IP, D'Hermies F, Hoang C, Gordon R, D'Alessandro A. Neotropical echinococcosis in Suriname: Echinococcus oligarthrus in the orbit and Echinococcus vogeli in the abdomen. The American Journal of Tropical Medicine and Hygiene 59: 787-790, 1998.
3. D'Alessandro A. Echinococosis neotropical en el hombre y los animales. Acta Médica del Valle 13: 99-109, 1982.

4. D'Alessandro A. Polycystic echinococcosis in tropical America: Echinococcus vogeli and E. oligarthrus. Acta Tropica 67:43-65, 1997.

5. D'Alessandro A, Moraes MAP, Raick AN. Polycystic hydatid disease in Brazil. Report of five new human cases and a short review of other published observations. Revista da Sociedade Brasileira de Medicina Tropical 29: 219-228, 1996. 